\title{
Mortality rates due to respiratory tract diseases in Tehran, Iran during 2008-2018: a spatiotemporal, cross-sectional study
}

Elahe Pishgar ${ }^{1}, Z$ Zohre Fanni ${ }^{1 *}$, Jamileh Tavakkolinia ${ }^{1}$, Alireza Mohammadi², Behzad Kiani ${ }^{3}$ and Robert Bergquist ${ }^{4}$

\begin{abstract}
Background: Tehran, the 22nd most populous city in the world, has the highest mortality rate due to respiratory system diseases (RSDs) in Iran. This study aimed to investigate spatiotemporal patterns of mortality due to these diseases in Tehran between 2008 and 2018.

Methods: We used a dataset available from Tehran Municipality including all cases deceased due RSDs in this city between 2008 and 2018. Global Moran's / was performed to test whether the age-adjusted mortality rates were randomly distributed or had a spatial pattern. Furthermore, Anselin Local Moran's / was conducted to identify potential clusters and outliers.

Results: During the 10-year study, 519,312 people died in Tehran, 43,177 because of RSDs, which corresponds to 831.1 per 10,000 deaths and 5.0 per 10,000 population. The death rate was much higher in men (56.8\%) than in women (43.2\%) and the highest occurred in the $>65$ age group (71.2\%). Overall, three diseases dominated the mortality data: respiratory failure (44.2\%), pneumonia (15.9\%) and lung cancer (10.2\%). The rates were significantly higher in the central and southeastern parts of the city and lower in the western areas. It increased during the period 2008-2018 and showed a clustered spatial pattern between 2008 and 2013 but presented a random geographical pattern afterwards.

Conclusions: This study provides a first report of the spatial distribution of mortality due to RSDs in Tehran and shows a significant increase in respiratory disease mortality in the last ten years. Effective control of the excess fatality rates would warrant a combination of urban prevention and treatment strategies including environmental health plans.
\end{abstract}

Keywords: Respiratory tract diseases, Mortality, Spatio-temporal analysis, Cluster analysis, Geographical information systems, Tehran, Iran

\footnotetext{
* Correspondence: Z-Fanni@sbu.ac.ir

'Department of Human Geography and Logistics, Faculty of Earth Science, Shahid Beheshti University, Tehran, Iran

Full list of author information is available at the end of the article
}

(c) The Author(s). 2020 Open Access This article is licensed under a Creative Commons Attribution 4.0 International License, which permits use, sharing, adaptation, distribution and reproduction in any medium or format, as long as you give appropriate credit to the original author(s) and the source, provide a link to the Creative Commons licence, and indicate if changes were made. The images or other third party material in this article are included in the article's Creative Commons licence, unless indicated otherwise in a credit line to the material. If material is not included in the article's Creative Commons licence and your intended use is not permitted by statutory regulation or exceeds the permitted use, you will need to obtain permission directly from the copyright holder. To view a copy of this licence, visit http://creativecommons.org/licenses/by/4.0/ The Creative Commons Public Domain Dedication waiver (http://creativecommons.org/publicdomain/zero/1.0/) applies to the data made available in this article, unless otherwise stated in a credit line to the data. 


\section{Background}

Respiratory system diseases (RSDs) represent a major disease burden including death across the world $[1,2]$. Although COVID-19 has recently put the respiratory system in focus, the RSDs were leading causes of death and disability already before the advent of this new infection. Indeed, the RSDs stand for five of the thirty most common causes of death worldwide [3, 4]. More than 9.5 million deaths globally are attributed to these diseases every year [5] and fourmillion people die prematurely from chronic respiratory diseases [3]. The most prevalent RSDs are chronic obstructive pulmonary diseases (COPD), asthma, acute lower respiratory tract infections, tuberculosis and lung cancer. Their incidence is affected by genetic disposition, gender, lifestyle and age, as well as environmental factors, such as the quality of air and water [4]. In Iran, the mortality rate due to respiratory system diseases (MRRSDs) was 9.8\% of total deaths in 2019 [6], with the level as high as $14 \%$ in the capital city Tehran. This means that 5000 people in Tehran die of RSDs every year, making it one of the most common causes of death in the city from 2008 to 2018 [7]. However, the high MRRSDs is not surprising as Tehran's population has passed 9 million and the extreme traffic and local industries constantly pollute the air [7]. Since the millennium shift, the municipality has made strong efforts to reduce air pollution by limiting traffic, prohibiting old cars, developing public transport and promoting decentralised residential areas; however, the problem remains despite these initiatives [8]. The high population concentration, the environmental diversity of the surrounding areas (windswept deserts, plains, and mountains) and the presence of many industries [9] have resulted in an extraordinary level of air pollution. There is thus a strong need for an analysis of the current epidemiological status of RSDs in Tehran with special regard to the potential spatial multiplicity of MRRSDs presence.

In recent years, most RSD studies have attempted to examine the association between these diseases and genetic dispositions together with physical activities and socio-economic status in urban environments [10-13]. For example, Apolloni et al. showed that higher assortment of contact patterns strongly increased the probability of spatial containment of the influenza A/H1N1 pandemic; this effect contrasted by an increase in the social activity of adults vs. children [10], while Niyonsenga et al. showed that spatial patterns were inversely related to area-level socio-economic status [11]. They confirmed the importance of individual-level covariates on the prevalence of COPD, especially the number of comorbid conditions as well as age, sex and smoking status [11]. Meanwhile, Adegboye et al. found that interventions to minimise mortality from the Middle East respiratory syndrome (MERS) coronavirus had a particular focus on individuals with co-morbidities, workers outside the health-care field and patients without clinical experience [12], and Chowell et al. noted a high geographic heterogeneity in the impact of the 1918-1919 influenza pandemic mortality in Spain [13]. Other studies have confirmed a significantly robust relationship between MRRSDs and ageing [14-16]. Lai et al. [17] incorporated stochastic processing of environmental and social variables that interact in space and time to affect the patterns of disease transmission in a community. They concluded that some RSDs, such as the severe acute respiratory syndrome (SARS) could potentially have turned into a pandemic helped by environmental determinants and spatial proximity. Their spatial model consistently yielded reliable results for predictions up to 10 days and could therefore aspire to be part of an early warning system (EWS). Other diseases, such as the H1N1 pandemic could change pattern and spread after retrogression and cessation [18].

Another group of previous studies [19, 20] focused on examining the correlation between RSDs and city air quality. In one such study, air pollution was reportedly the cause of $11.2 \%$ deaths in the world [21]. Similar studies have been carried out in Tehran, where Mohammadi et al. [22] confirmed increased hospital referrals in December and January of patients with respiratory ailments caused by low temperatures and high-pressure weather conditions leading to inversion and low, dense smoke. Other studies in Tehran [23-28] have found a strong direct relationship between the high density of air gaseous pollutants $\left(\mathrm{O}_{3}, \mathrm{NO}_{2}\right)$ and micro $(\mu \mathrm{m})$ particulate matter $\left(\mathrm{PM}_{2.5}, \mathrm{PM}_{10}\right)$ on the one hand and RSDs on the other. Not surprisingly, smoking is strongly associated with mortality and hospitalisation [26]. Some studies have reported that these pollutants can exacerbate respiratory and pneumonia failure and eventually lead to death [29, 30]. Research shows that genetic factors, smoking, alcohol consumption, radiation exposure and industrial smoke as well as certain occupations and work environment are related to lung cancer [31].

Identification of specific epidemiological patterns helps to implement preventive strategies, which are of special importance in cities where air pollution has a direct impact on RSDs [10,13]. Geographical information systems (GIS) makes it possible to identify spatiotemporal relationships between disease and mortality by combining spatial and temporal data [32], and a few epidemiological studies related to RSDs have been carried out in Iran [33-35]. For example, Sharifi et al. [36] studied risk factors for COPD applying a stratified cluster sampling method in five provinces of Iran, including Tehran. They concluded that less exposure to environmental factors reduces COPD considerably. Yazdani et al. [37] examined tuberculosis (TB) in the province of Mazandaran reporting a heterogeneous spatial pattern regarding the 
prevalence of this disease. Their findings showed that the TB spatial pattern followed variations in age, sex or population density. Researchers identified hot and cold spots in terms of disease prevalence rate in the study area. Qanbarzadeh et al. [38] investigated the same disease in South Iran, similarly finding clustering of TB cases and the role of spatial factors such as population density. In another but similar study, Khazaei et al. [39] used geographical maps to explore TB prevalence in western Iran, concluding that it had increased by $6.4 \%$ between 1992 and 2013, although there were prevalence differences in some regions. Apart from these studies, researchers have been reluctant to apply spatiotemporal methods to analyse RSD data. In particular, the studies have mainly focused on one disease, e.g., influenza [13].

To our knowledge, no study on the spatiotemporal patterns of MRRSDs in Tehran has been done, so we explored this, while also attempting to identify high-risk and low-risk regions in terms of MRRSDs. In addition, since this study was conducted before the COVID-19 pandemic, it provides base data that can be beneficial for future comparison of the effect of COVID-19 pandemic on MRRSDs in Tehran districts.

\section{Methods \\ Study area}

Tehran, the capital of Iran consists of 22 municipality districts and is located at $35.68 .92 \mathrm{~N}$ latitude and 51.38.90 E longitude. It is bordered by mountains in the North, plains and urban regions in the West, dry areas in the East and the central deserts of Iran in the South (Fig. 1). According to the latest estimations 2019, the population varies between $8,680,000$ at night and around $10,000,000$ daytime $[40,41]$. It covers an area of $730 \mathrm{~km}^{2}$ with a population density of 11,890 per $\mathrm{km}^{2}$ [40]. It has a climate with four entirely different seasons [9]. The average annual air temperature in Tehran varies between $15^{\circ} \mathrm{C}$ and $18^{\circ} \mathrm{C}$ [42].

\section{Data gathering and preparation}

Data on persons deceased due to RSDs from 2008 to 2018 were obtained from the Behesht-e Zahra

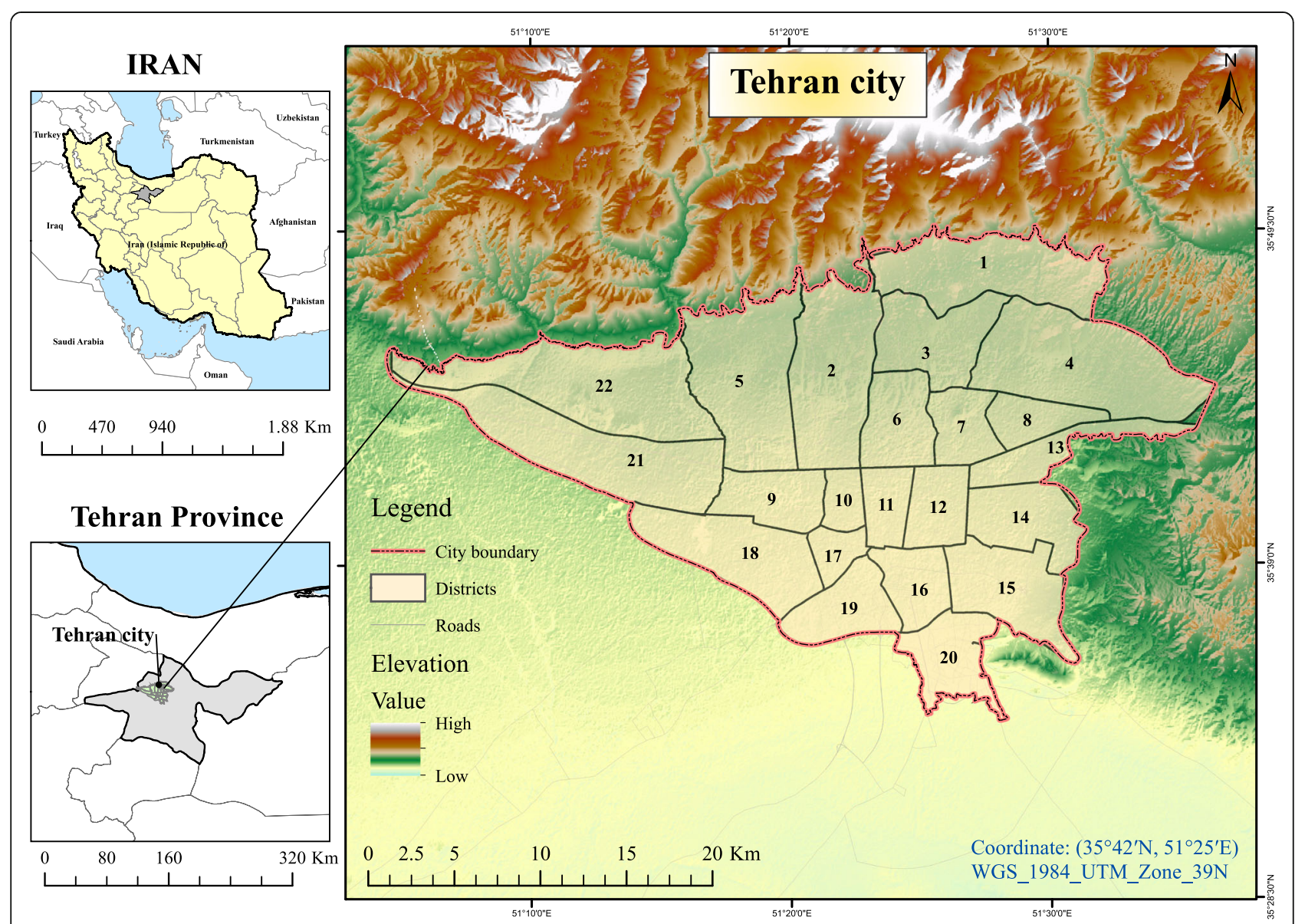

Fig. 1 The 22 districts of the city of Tehran. Authors acknowledge the Tehran Municipality for providing the shape file of Tehran districts used to create this map. The shapefile is freely available from https://map.tehran.ir. The elevation data is freely available from https://earthexplorer.usgs. gov. The image was created by ArcGIS 10.7 (ESRI, Redlands, CA, USA) 
Organization, a local health department under the supervision of the Tehran Municipality [7]. This dataset includes date of death, age, diagnosis (kind of respiratory disease) and place of residency. Population data were obtained from the statistical centre of Iran [40].

\section{Calculating age and sex-adjusted MRRSDs}

We utilised five age groups, 0-14, 15-24, 25-44, 45-64 and $>65$ years, of the census population as basis for our analysis [9]. We calculated the age and sex-adjusted MRRSDs for each district for every year from 2008 to 2018 separately.

\section{Spatial analysis}

There are various methods for measuring spatial autocorrelation. The global methods are more sensitive to departures from the null hypothesis (random distribution) but do not tell where the clusters are, which is possible when applying the local methods [43]. We used Global Moran's Index (GMI) [44, 45] and Anselin's Local Moran's Index (ALMI) $[45,46]$ since they, according to the literature [44, $45,47,48]$, are generally more accurate with regard to measuring autocorrelation than other statistics. The radius for the base of proximity analysis was set at $9690.01 \mathrm{~m}$ to calculate the GMI and ALMI and the inverse distance method was performed to show spatial relationships. The level of statistical significance was set at $p=0.05$.

The WGS_1984_UTM_Zone_39N projection system was used for projecting the GIS layers. This projection is a mathematical transformation that transforms spherical coordinates (latitude and longitude) into an XY (planar) coordinate system enabling researchers to create a map that accurately shows distances, areas or directions [49]. WGS_1984_UTM_Zone_39N is suitable for use between $54^{\circ} \mathrm{E}$ and $60^{\circ} \mathrm{E}$, and in the northern hemisphere between the equator and $84^{\circ} \mathrm{N}$, onshore and offshore. We used this projection system because the study area is located around $51^{\circ} \mathrm{E}$ and $35^{\circ} \mathrm{N}$.

\section{Software}

Microsoft Excel 2016 and Origin were applied for preparing and encoding the data and drawing diagrams. ArcGIS 10.7 (ESRI, Redlands, CA, USA) was used for performing the spatial statistics. After preparing the initial data, the information was added to the map of Tehran in the ArcGIS environment. The 'Spatial Statistics Tools' including 'Spatial Autocorrelation (GMI)' and 'Cluster and Outlier Analysis (ALMI)' were used to implement the analyses.

\section{Results}

Descriptive results

In the 22 municipality districts of Tehran, a total of 43, 177 persons died due to RSDs from 2008 to 2018.
During these ten years, the MRRSD average was 5.0 per 10,000 , with men being at higher risk of death than women (56.8\% versus $43.2 \%)$. The average of 1.9 per 10 , 000 in 2008 had quadrupled to 7.5 per 10,000 deaths in 2018. Figure 2-A reveals a continually ascending trend of MRRSDs over the ten years of the study, particularly after 2015 (4.8 per 10,000). The mean MRRSDs was 2.9 for males and 2.1 for females (Fig. 2-a). Fig. 2-b shows the MRRSDs separately by gender and age groups, indicating that $71.2 \%$ of the deaths occurred in the age group $>65$ years. Figure 2-c, depicting the MRRSDs by municipality district, reveals that district 12 had the highest rate and district 21 the lowest. As seen in Fig. 1, district 12 is located in the centre of Tehran (downtown) and district 21 in the western part of the city.

Figure 2-c reveals that district 12 encountered higher seasonal MRRSDs compared to the other areas during all four seasons throughout the time covered by the study. District 21 and 22 that are located in the western part of the city had the lowest seasonal mortality rates. Most seasonal rates were observed during winter and autumn. Furthermore, the highest rates were often observed in the central and southeastern regions, while those located in the West encountered low rates (Fig. 4).

\section{Cause of mortality}

Thirty-four leading causes of death were related to RSDs in the data obtained from Tehran Municipality. Out of these causes, the following MRRSD groups dominated (91.2\%) the picture in Tehran: respiratory failure (44.2\%), pneumonia (15.9\%), lung cancer (10.2\%), pulmonary diseases (exact type not given) (8.6\%), pulmonary embolism (5.5\%), lung oedema (3.9\%) and respiratory infections (2.1\%) (Fig. 3).

\section{Spatiotemporal results Annual rates}

Figure 4 shows the age-adjusted MRRSDs from 2008 to 2018 for both genders in the 22 municipality districts of Tehran. It is obvious that the total number of ageadjusted MRRSDs has increased considerably from 2008 to 2018; for instance, the overall mortality in district 12 (downtown) increased from 2.9 per 10,000 to 19.3. Moreover, the overall geographical distribution of MRRS Ds also increased over the ten-year study period from 5 to 19 high-rate districts over the study period.

Compared to other areas, the rate of age-adjusted MRRSDs was considerably less in the western parts of Tehran. Some of the southern and central parts of the city encountered high rates throughout the study. Figure $4(k-t)$ shows that the male mortality rates were considerably different from both the female ones and the total. According to Fig. 4(u-d'), at the end of the period in 2018 and among all regions, the maximum rate of age-adjusted MRRSDs 

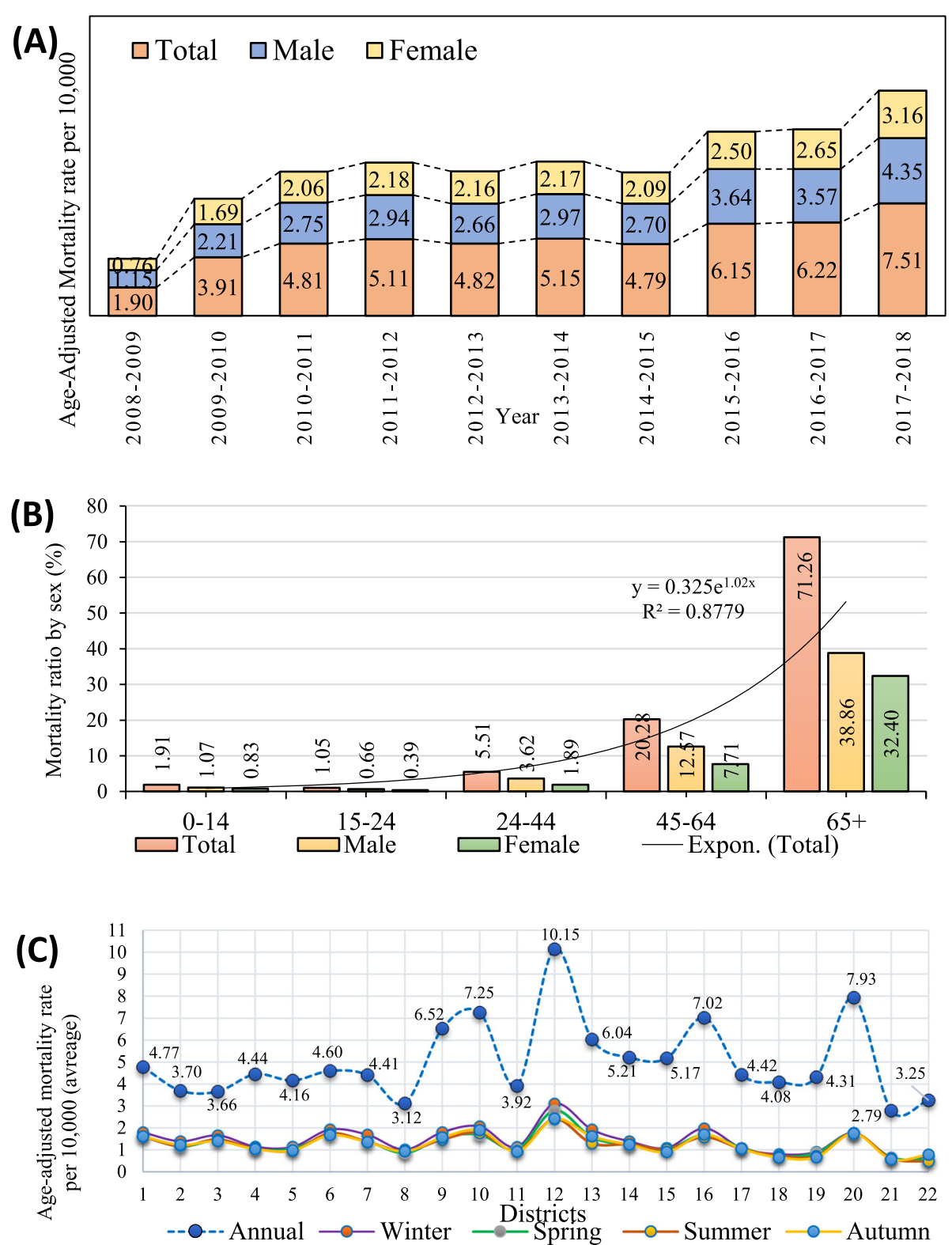

Fig. 2 Age-adjusted annual and seasonal mortality rates of respiratory system diseases per 10,000

was not higher than 7.7 per 10,000 for women, which is in contrast to the male mortality at 11.6 and the total at 10.1.

\section{Spatial autocorrelation}

Table 1 shows the results of applying GMI for the age-adjusted MRRSDs per 10,000 from 2008 to 2018. The dominant pattern of spatial autocorrelation was that of the high clustering (HC) from 2008 to 2010. However, there was low clustering (LC) during 2010$2013(P<0.07)$; therefore, the null hypothesis (lack of spatial autocorrelation) was rejected for the period 2008-2012. The spatial distribution pattern changed gradually from 2013 to 2018, eventually confirming the null hypothesis. In other words, random spatial autocorrelation was observed in this period $(P>0.1)$. Performing analysis by gender showed that MRRSDs in females was only high-clustered in two of the years (Table 1).

\section{Cluster and outlier analysis}

Figure 5 shows the results of ALMI in terms of the total annual age-adjusted MRRSDs. Districts 15 and 16 exhibited a high-high (HH) cluster from 2008 to 2013, while some regions, e.g., district 11 showed a low-high (LH) cluster from 2008 to 2018 and district 22 was in a lowlow (LL) cluster $(P<0.05)$ at that time. ALMI results by 


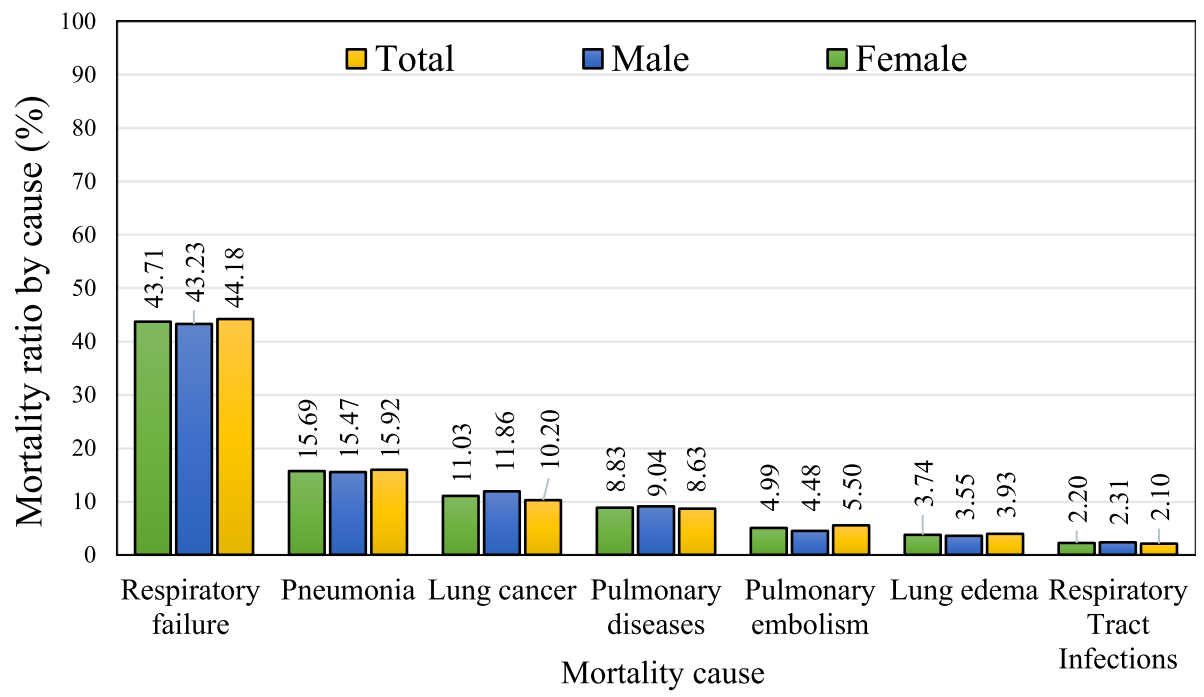

Fig. 3 Respiratory system diseases caused deaths by sex, Tehran, 2008-2018

sex followed that of the total age-adjusted MRRSDs with few changes. It faded gradually from 2014 to 2018 and then turned into a random pattern. It means that MRRS Ds have reached other regions of Tehran in recent years. Thus, despite the increase in deaths during the period, for reasons not covered in this study, MRRSDs have spread to other districts but with no MRRSD clusters in recent years.

\section{Discussion}

Respiratory failure (44.2\%), pneumonia (15.9\%), and lung cancer $(10.2 \%)$ were found to be the leading causes of death among respiratory patients in our study. This is expected due to the highly polluted environment of Tehran, specifically in relation to presence of increased levels of $\mathrm{NO}_{2}$ and $\mathrm{PM}_{2.5}$ [8]. These pollutants can intensify respiratory failures and pneumonia, leading to death in the long term $[28,50]$. In addition, social-economic factors and immobility predispose for an increased incidence of COPD [51, 52]. Since most providers of cigarettes and water pipes are more common in the southeastern parts of the city than other municipalities [40], these results are in line with previous studies confirming that smoking in Tehran increases the incidence of lung cancer [26]. Rohani- Rasaf et al. [53] concluded that the death rate from cancers, including lung cancer, has increased over time in Tehran's lower socio-economic districts. Furthermore, previous studies $[26,53]$ have shown that lung cancer is responsible for increasing of death rates, especially in the elderly in some districts (e.g. district 12); as in this study, those areas also had high mortality rates.

Our results show that age-adjusted MRRSDs almost quadrupled from 2008 to 2018 but was slightly lower in
2012 and 2013. The cause(s) of this increase are not known but could include increased air pollution, smoking, overcrowding and other potential environmental risk factors. Our results also show that the rate of ageadjusted MRRSDs was higher in men than women, which is in line with the results by Yu et al. [16], who reported an even more significant difference $(81.2 \%$ versus 18.2\%) in Changzhou, China. This is not surprising as men are supposedly more exposed to environmental factors than women [23]. The age-adjusted MRRSDs were higher in the $>65$ years age group, which has also been reported in various geographical regions [14-16].

It was noted that the central and southeastern parts of Tehran had the highest rate of MRRSDs (Fig. 4) and also most businesses and official buildings are situated in these areas; For instance, the high-MRRSD district 12 includes not only crowded driveways but also has the highest number of gas stations [54, 55]. The western parts of Tehran, characterised by a relatively low population density and fewer buildings, had the lowest MRRS Ds rate. Furthermore, this area is exposed to dominant winds, is geographically elevated and has natural air ducts [9]. The southern areas, in contrast, is the site of big industrial workshops and the amount of air pollution is higher in southern parts [40], which can be an explanation for the high MRRSDs rate found in this part of the city.

We also saw the MRRSDs gradually and significantly increase from 2008 to 2018; for instance, the total MRRS Ds went from 2.8 per 10,000 in the western parts to 10.1 in the central parts. These results are in line with those of other researchers [56], who state that the increase in mortality is due to the high number of RSDs in Tehran. The results of analysing the seasonal rates pattern 


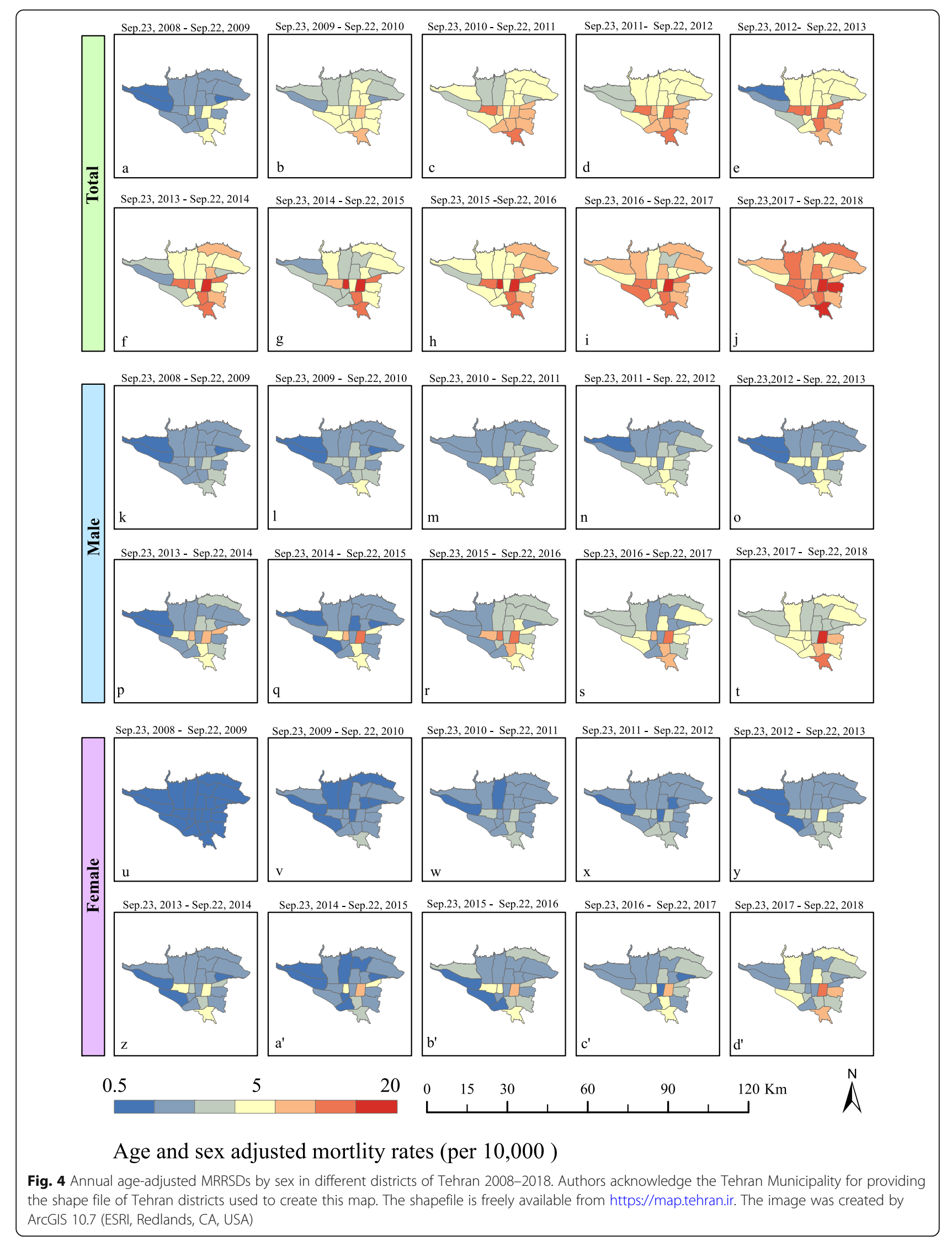




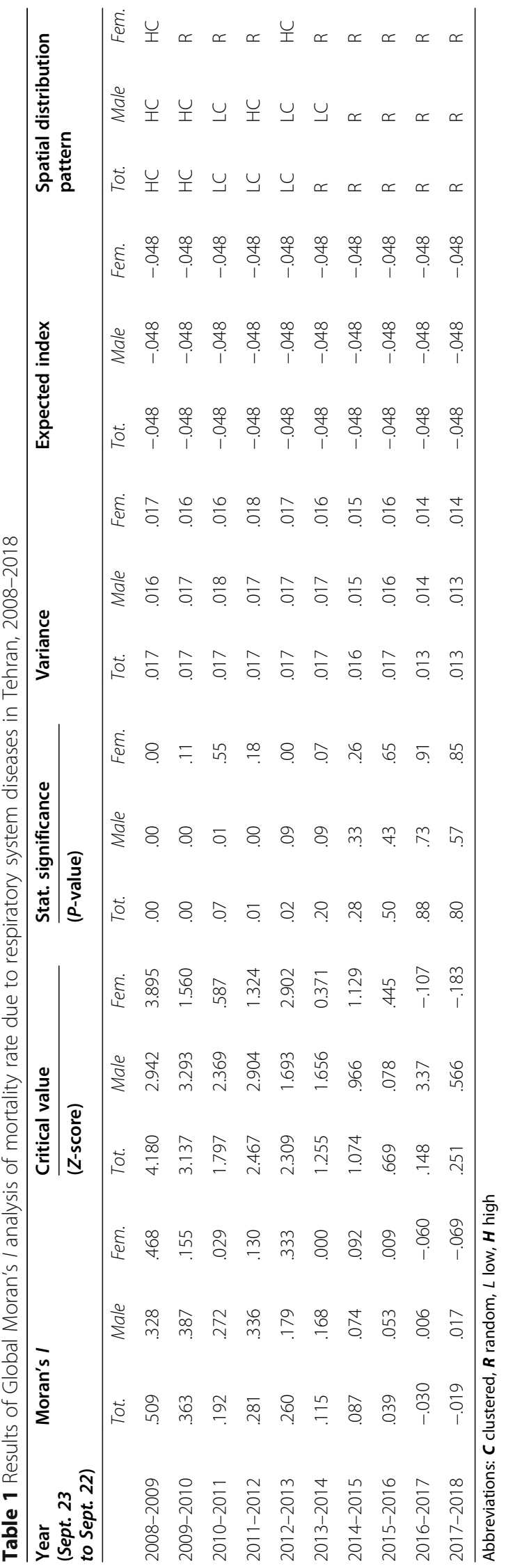




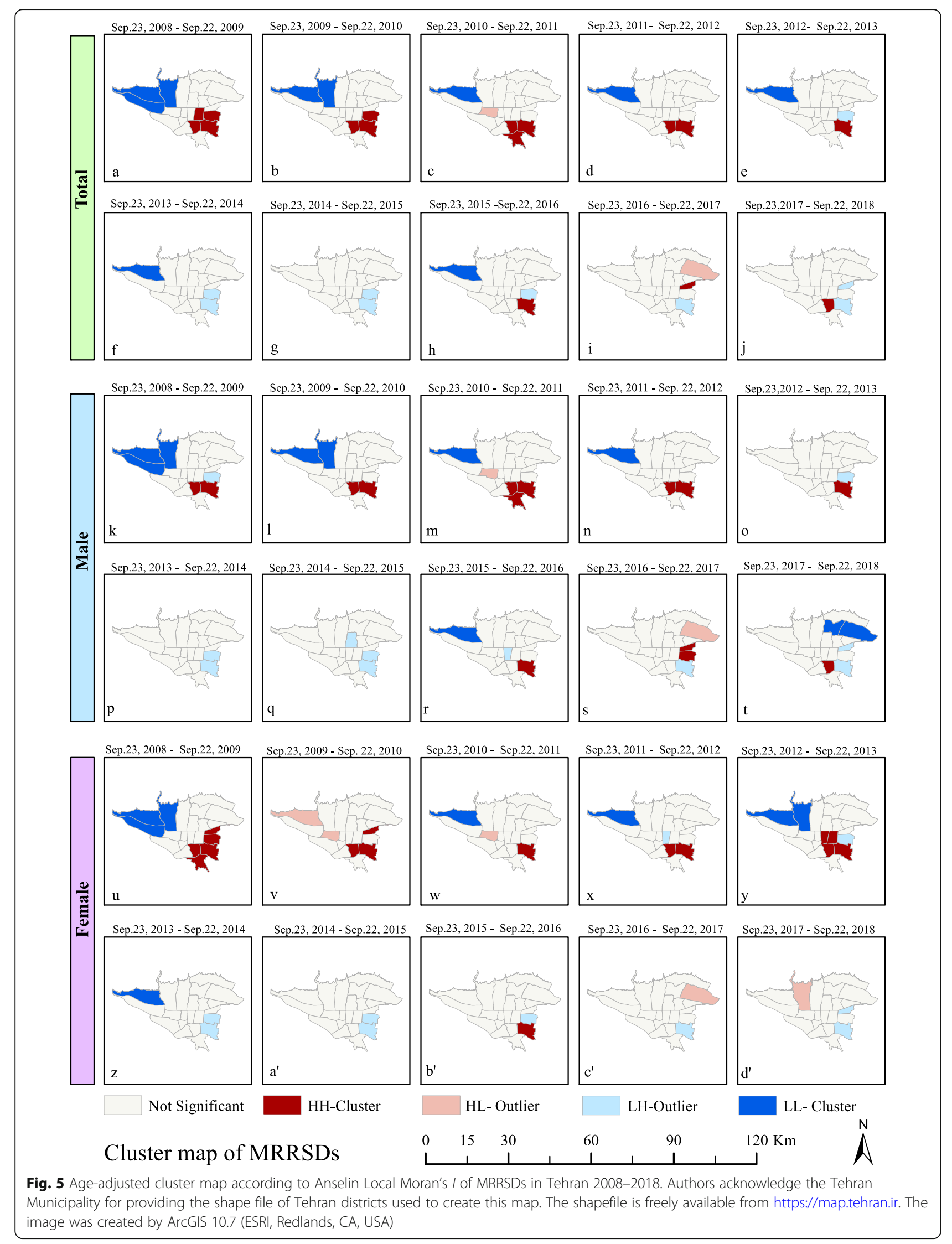


showed that high rates in some parts of the city (District 12 in downtown) and low rates in the other parts (district 21 in the West) repeated year by year along the season changes in winter and autumn. Inversion happens in autumn along with the educational centres' activity and gradual temperature drop; therefore, the highest air pollution generally appears in the autumn [41]. Having examined Tehran records, it was obvious that the air pollution index was commonly higher during the autumn-winter period from 2013 to 2018 [57]. As some researchers have reported, MRRSDs can significantly increase during the cold season [16, 17, 19-22].). In addition to air pollution, increased respiratory deaths in winter is likely due to increased respiratory infections. Another possible cause of seasonal differences could be temperature (increased deaths with cold temperature). It should be noted that all of these reasons presented in this study are hypotheses that should be considered in future studies.

\section{Recommendations}

An association with of elevated values of certain factors leading to RSDs mortality in megacities has been shown by this study and others. It is now up to the authorities to create and enforce policies leading to long-term reduction of these factors. It is recommended to combine social policies like decreasing tobacco usage with urban planning. Giving license to pollutant businesses should be limited in some regions like central and southeastern districts that now have the highest MRRSDs. Examining and promoting safety and health in working environments, especially in regions with high mortality rates in men can help to decrease the development of RSDs and overall mortality. Clean public transports infrastructure (electric cars) and removal of factories from the southeastern parts of Tehran would probably assist prevention of respiratory diseases there.

\section{Limitations}

Mortality statistics of smaller urban scales were not available. Therefore, we chose urban districts as the analytical basis.

\section{Conclusions}

Our findings indicate a significant increase in respiratory disease mortality in Tehran in the last 10 years. Furthermore, the spatiotemporal distribution of MRRS Ds in Tehran follows a heterogenic pattern after 2013. Considering effective control of MRRSDs would warrant a combination of prevention and treatment strategies through urban planning including environmental pollutant control and environmental health plans. This should be taken into consideration by health policymakers when facing the increasing risk of mortality in relation to environmental factors.

\section{Abbreviations}

RSDs: Respiratory system diseases; COPD: Chronic obstructive pulmonary diseases; MRRSDs: 'Mortality rates due to respiratory system diseases; SARS: Sever acute respiratory syndrome; GIS: Geographical information systems; GMI: Global Moran's Index; ALMI: Anselin's local Moran Index; LISA: Local indicators of spatial autocorrelation; HC: High-clustered; LH: Lowclustered

\section{Acknowledgements}

The authors thank the Tehran Municipality (TM) for providing Tehran's mortality data.

\section{Authors' contributions}

E.P analysed and interpreted the death data. Z. F and J. T were the principal investigators of the study. A. M and B. K designed the study, drafted the manuscript and revised the manuscript according to reviewers' comments. $B$. $K$ and $R$. B revised the draft and approved the final version for submission. $B$. $K$ responded to the reviewers' comments and supervised the research. All authors read and approved the final manuscript.

\section{Funding}

This research did not receive any grants from funding agencies in the public, commercial, or not-for-profit sectors.

\section{Availability of data and materials}

Raw data on persons deceased due to RSDs from 2008 to 2018 were obtained from the Behesht-e Zahra Organization, a local health department under the supervision of the Tehran Municipality. There is no permission to obtain the datasets and they are available from the corresponding author on request.

Ethics approval and consent to participate

Not applicable.

\section{Consent for publication \\ Not Applicable.}

\section{Competing interests}

The authors declare that they have no known competing for financial interests or personal relationships that could have appeared to influence the work reported in this paper.

\section{Author details}

${ }^{1}$ Department of Human Geography and Logistics, Faculty of Earth Science, Shahid Beheshti University, Tehran, Iran. ²Department of Geography and Urban Planning, Faculty of Social Sciences, University of Mohaghegh Ardabili, Ardabil, Iran. ${ }^{3}$ Department of Medical Informatics, School of Medicine, Mashhad University of Medical Sciences, Mashhad, Iran. ${ }^{4}$ Ingerod, Brastad, Sweden (formerly with the UNICEF/UNDP/World Bank/WHO Special Programme for Research and Training in Tropical Diseases, World Health Organization), Geneva, Switzerland.

Received: 14 April 2020 Accepted: 3 September 2020 Published online: 17 September 2020

\section{References}

1. Steppuhn H, Buda S, Wienecke A, Kraywinkel K, Tolksdorf K, Haberland J, et al. Time trends in incidence and mortality of respiratory diseases of high public health relevance in Germany; 2017. https://doi.org/10.17886/RKI-GBE2017-061.

2. Zar HJ, Ferkol TW. The global burden of respiratory disease-impact on child health. Pediatr Pulmonol. 2014;49(5):430-4. https://doi.org/10.1002/ ppul.23030

3. Paul E, Brown GW, Ridde V. COVID-19: time for paradigm shift in the nexus between local, national and global health. BMJ Glob Health. 2020;5(4): e002622. https://doi.org/10.1136/bmjgh-2020-002622.

4. Forum of International Respiratory Societies (FIRS). In: Edition S, editor. The Global Impact of Respiratory Disease. 2nd ed. Sheffi eld: European Respiratory Society; 2017. p. 42. https://www.who.int/gard/publications/The Global_Impact_of_Respiratory_Disease.pdf. Accessed 21 March 2020. 
5. Wong AH, Tran T. CD151 in respiratory diseases. Front Cell Dev Biol. 2020;8: 64. https://doi.org/10.3389/fcell.2020.00064.

6. National Organization For Civil Registration (NOCR). Yearbook of Demographic Statistics 2019. Tehran: Bureau of Demographic and Immigration Statistics; 2020. p. 304-6. https://www.sabteahval.ir/avej/default. aspx?tabid=1499. Accessed on 31 January 2020, Contract No.

7. Beheshte-e Zahra Organization (BZO). 2019 ed. Tehran: Tehran municipality; 2019.

8. Tehran's Air Quality Control Company (TAQCC). Tehran's Annual Air Quality Report 2018. Tehran: Tehran Municipality; 2019. Contract No.: 02/29/2019. http://airnow.tehran.ir/home/AirQuality.aspx. Accessed 22 November 2019.

9. Tehran Municipality (TM). Atlas of Tehran Metropolis. Tehran; 2018. http:// atlas.tehran.ir/. Accessed 23 April 2020.

10. Apolloni A, Poletto C, Colizza V. Age-specific contacts and travel patterns in the spatial spread of 2009 H1N1 influenza pandemic. BMC Infect Dis. 2013; 13(1):176. https://doi.org/10.1186/1471-2334-13-176.

11. Niyonsenga T, Coffee N, Del Fante P, Høj S, Daniel M. Practical utility of general practice data capture and spatial analysis for understanding COPD and asthma. BMC Health Serv Res. 2018;18(1):897 https://doi.org/10.1186/ s12913-018-3714-5.

12. Adegboye OA, Gayawan E, Hanna F. Spatial modelling of contribution of individual level risk factors for mortality from Middle East respiratory syndrome coronavirus in the Arabian peninsula. PLoS One. 2017;12(7): e0181215. https://doi.org/10.1371/journal.pone.0181215.

13. Chowell G, Erkoreka A, Viboud C, Echeverri-Dávila B. Spatial-temporal excess mortality patterns of the 1918-1919 influenza pandemic in Spain. BMC Infect Dis. 2014;14(1):371. https://doi.org/10.1186/1471-2334-14-371.

14. Khajavi A, Khalili D, Azizi F, Hadaegh F. Impact of temperature and air pollution on cardiovascular disease and death in Iran: a 15-year follow-up of Tehran lipid and glucose study. Sci Total Environ. 2019;661:243-50 https:// doi.org/10.1016/j.scitotenv.2019.01.182.

15. Killien EY, Mills B, Vavilala MS, Watson RS, O'Keefe GE, Rivara FP. Association between age and acute respiratory distress syndrome development and mortality following trauma. J Trauma Acute Care Surg. 2019;86(5):844-52. https://doi.org/10.1097/ta.0000000000002202.

16. Ma Y, Zhou J, Yang S, Yu Z, Wang F, Zhou J. Effects of extreme temperatures on hospital emergency room visits for respiratory diseases in Beijing, China. Environ Sci Pollut Res. 2019;26(3):3055-64. https://doi.org/10. 1007/s11356-018-3855-4

17. Lai P-C, Kwong K-H, Wong H-T. Spatio-temporal and stochastic modelling of severe acute respiratory syndrome. Geospat Health. 2013;8(1):183-92. https://doi.org/10.4081/gh.2013.65.

18. Chowell G, Towers S, Viboud C, Fuentes R, Sotomayor V, Simonsen L, et al. The influence of climatic conditions on the transmission dynamics of the 2009 a/H1N1 influenza pandemic in Chile. BMC Infect Dis. 2012;12(1):298. https://doi.org/10.1186/1471-2334-12-298.

19. Parenteau M-P, Sawada MC. The modifiable areal unit problem (MAUP) in the relationship between exposure to NO 2 and respiratory health. Int J Health Geogr. 2011;10(1):58. https://doi.org/10.1186/1476-072X-10-58.

20. Rushworth A, Lee D, Mitchell R. A spatio-temporal model for estimating the long-term effects of air pollution on respiratory hospital admissions in greater London. Spat Spatio-Temporal Epidemiol. 2014;10:29-38. https://doi. org/10.1016/j.sste.2014.05.001.

21. Bernardo A, Gonçalves LL, Zagalo C, Brito J. Relationships between air pollutants and mortality in Portugal - an environmental health assessment. Ann Med. 2019;51(sup1):69. https://doi.org/10.1080/07853890.2018.1561623.

22. Mohammadi H, Cohen D, Babazadeh M, Rokni L. The effects of atmospheric processes on Tehran smog forming. Iran J Public Health. 2012;41(5):1-12 https://www.ncbi.nlm.nih.gov/pubmed/23113173.

23. Dehghan A, Khanjani N, Bahrampour A, Goudarzi G, Yunesian M. The relation between air pollution and respiratory deaths in Tehran, Iran-using generalized additive models. BMC Pulm Med. 2018;18(1):49. https:/doi.org/ 10.1186/s12890-018-0613-9.

24. Karimi B, Samadi S. Mortality and hospitalizations due to cardiovascular and respiratory diseases associated with air pollution in Iran: a systematic review and meta-analysis. Atmos Environ. 2019;198:438-47. https://doi.org/10.1016/ j.atmosenv.2018.10.063.

25. Khaniabadi YO, Sicard P, Takdastan A, Hopke PK, Taiwo AM, Khaniabadi FO, et al. Mortality and morbidity due to ambient air pollution in Iran. Clin Epidemiol Global Health. 2019;7(2):222-7. https://doi.org/10.1016/j.cegh. 2018.06.006.
26. Masjedi MR, Taghizadeh F, Hamzehali S, Ghaffari S, Fazzzadeh M, Jafari AJ, et al. Air pollutants associated with smoking in indoor/outdoor of waterpipe cafés in Tehran, Iran: concentrations, affecting factors and health risk assessment. Sci Rep. 2019;9(1):1-11. https://doi.org/10.1038/s41598-01939684-3.

27. Mohammadi A, Azhdarpoor A, Shahsavani A, Tabatabaee H. Investigating the health effects of exposure to criteria pollutants using AirQ2. 2.3 in shiraz, Iran. Aerosol Air Qual Res. 2016;16(4):1035-43. https://doi.org/10.4209/aaqr. 2015.07.0434.

28. Sharifi S, Karami M, Esmailnasab N, Rooshanaei G. Association between increased air pollution and mortality from respiratory and cardiac diseases in Tehran: application of the GLARMA model. Iran J Epidemiol. 2017;12(4): 36-43 http://irje.tums.ac.ir/article-1-5619-en.html.

29. Koivula I, Sten M, Makela PH. Risk factors for pneumonia in the elderly. Am J Med. 1994;96(4):313-20. https://doi.org/10.1016/0002-9343(94)90060-4.

30. Loeb M, McGeer A, McArthur M, Walter S, Simor AE. Risk factors for pneumonia and other lower respiratory tract infections in elderly residents of long-term care facilities. Arch Intern Med. 1999;159(17):2058-64. https:// doi.org/10.1001/archinte.159.17.2058.

31. Malhotra J, Malvezzi M, Negri E, La Vecchia C, Boffetta P. Risk factors for lung cancer worldwide. Eur Respir J. 2016;48(3):889-902. https://doi.org/10. 1183/13993003.00359-2016.

32. Hashtarkhani S, Kiani B, Bergquist R, Bagheri N, VafaeiNejad R, Tara M. An age-integrated approach to improve measurement of potential spatial accessibility to emergency medical services for urban areas. Int J Health Plann Manag. 2020;35(3):788-98. https://doi.org/10.4081/gh.2018.703.

33. Kiani B, Bagheri N, Tara A, Hoseini B, Hashtarkhani S, Tara M. Comparing potential spatial access with self-reported travel times and cost analysis to haemodialysis facilities in North-eastern Iran. Geospat Health. 2018;13(2). https://doi.org/10.4081/gh.2018.660.

34. Minale AS, Alemu K. Mapping malaria risk using geographic information systems and remote sensing: The case of Bahir Dar City, Ethiopia. Geospat Health. 2018;13(1). https://doi.org/10.1002/hpm.3010.

35. Kiani B, Raouf Rahmati A, Bergquist R, Moghaddas E. Comparing spatiotemporal distribution of the most common human parasitic infections in Iran over two periods 2007 to 2012 and 2013 to 2018: a systematic quantitative literature review. Int J Health Plann Manag. 2020. https://doi. org/10.4103/lungindia.lungindia_129_18.

36. Sharifi $H$, Ghanei M, Jamaati H, Masjedi MR, Aarabi M, Sharifpour A, et al. Burden of obstructive lung disease study in Iran: first report of the prevalence and risk factors of COPD in five provinces. Lung India. 2019; 36(1):14. https://doi.org/10.5539/gjhs.v6n6p288.

37. Yazdani-Charati J, Siamian H, Kazemnejad A, Vahedi M. Spatial clustering of tuberculosis incidence in the north of Iran. Global J Health Sci. 2014;6(6):288. https://doi.org/10.5539/gjhs.v6n6p288.

38. Qanbarnezhad A, Roustazadeh A, Alizadeh A, Abbastabar H, Nazarnezhad M, Mohseni S. Spatial distribution of TB and HIV co-infection in south of Iran. JAdv Pharm Educ Res. 2018;8(S2) http://htdo.jums.ac.ir/dorsapax/Data/sub_2 9/file/Spatial\%20Distribution\%20of\%20TB\%20and\%20HIV\%20Co.pdf. Accessed 08 August 2020.

39. Khazaei S, Nematollahi S, Doosti-Irani A, Zahiri A, Mofarrah-Zat A, Ayubi E, et al. Spatio-temporal analysis of tuberculosis in Hamadan Province, west of Iran, from 1992 to 2013. Tanaffos. 2019;18(1):18-24 http://europepmc.org/ abstract/MED/31423136.

40. Tehran Municipality (TM). Tehran Statistical yearbooks 2006-2017. PDF formatfile. Tehran: Tehran Municipality, organization I; 2019. Report No.: 1.

41. Heger M, Sarraf M. Air pollution in Tehran: health costs, sources, and policies. World Bank. 2018. https://doi.org/10.1596/29909.

42. Bokaie M, Zarkesh MK, Arasteh PD, Hosseini A. Assessment of urban heat island based on the relationship between land surface temperature and land use/land cover in Tehran. Sustain Cities Soc. 2016;23:94-104. https:// doi.org/10.1016/j.scs.2016.03.009.

43. Halimi L, Bagheri N, Hoseini B, Hashtarkhani S, Goshayeshi L, Kiani B. Spatial analysis of colorectal cancer incidence in Hamadan Province, Iran: a retrospective cross-sectional study. Appl Spat Anal Policy. 2019:1-11. https:// doi.org/10.1007/s12061-019-09303-9.

44. Anselin L, Syabri I, Kho Y. GeoDa: an introduction to spatial data analysis. Geogr Anal. 2006;38(1):5-22. https://doi.org/10.1111/j.0016-7363. 2005.00671.x.

45. Dubé J, Legros D. Spatial Autocorrelation: John Wiley \& Sons, Inc.; 2014. p. 59-91. https://doi.org/10.1002/9781119008651.ch1. 
46. Goshayeshi L, Pourahmadi A, Ghayour-Mobarhan M, Hashtarkhani S, Karimian S, Dastjerdi RS, et al. Colorectal cancer risk factors in north-eastern Iran: A retrospective cross-sectional study based on geographical information systems, spatial autocorrelation and regression analysis. Geospat Health. 2019;14(2). https://doi.org/10.4081/gh.2019.793.

47. Asgari A. Analysis of spatial statistics using ARCGIS: processing and urban planning $\mathrm{CO} ; 2011$.

48. Environmental Systems Research Institute, 'ESRII. ArCGIS 10.5 Tutorial: ESRI; 2018 [Available from: https://www.esri.com/en-us/arcgis/products/arcgispro/overview. Accessed 20 March 2020

49. Shabanikiya $H$, Hashtarkhani S, Bergquist R, Bagheri N, VafaeiNejad R, AmiriGholanlou M, et al. Multiple-scale spatial analysis of paediatric, pedestrian road traffic injuries in a major city in north-eastern Iran 2015-2019. BMC Public Health. 2020;20:1-11. https://doi.org/10.1186/s12889-020-08911-2.

50. Gholizadeh M, Farajzadeh M, Darand M. The correlation between air pollution and human mortality in Tehran. Hakim Res J. 2009;12(2):65-71 http://hakim.hbi.ir/article-1-523-en.html.

51. De Marco R, Accordini S, Marcon A, Cerveri I, Antó JM, Gislason T, et al. Risk factors for chronic obstructive pulmonary disease in a European cohort of young adults. Am J Respir Crit Care Med. 2011;183(7):891-7. https://doi.org/ 10.1164/rccm.201007-1125OC.

52. Reilly KH, Gu D, Duan X, Wu X, Chen C-S, Huang J, et al. Risk factors for chronic obstructive pulmonary disease mortality in Chinese adults. Am J Epidemiol. 2008;167(8):998-1004. https://doi.org/10.1093/aje/kwm393.

53. Rohani-Rasaf M, Rohani-Rasaf MR, Asadi-Lari M, Hashemi Nazari SS. Regional differences in cancer incidence trend in tehran, Iran: A contextual study on the effect of socioeconomic status at regional level. Int J Cancer Manage. 2018;11(1). https://doi.org/10.5812/ijcm.664.

54. Tehran Municipality (TM). Detailed Plan of Tehran Region 22. Tehran; 2015. https://www.shahrsazionline.com. Accessed January 242020.

55. Salehi E. A report on the environmental status of Tehran. Tehran; 2010 http://rpc.tehran.ir/Default.aspx?tabid=1324. Accessed 10 November 2019.

56. Rezaei Kalantari R, Kermani M, Dowlati M, Jonidi JA. Number of mortality, chronic obstructive pulmonary disease and acute myocardial infarction due to exposure to sulfur dioxide in Tehran, during 2005-2014. koomesh. 2018; 20(1):34-42 http://koomeshjournal.semums.ac.ir/article-1-3779-fa.html.

57. Tehran's Air Quality Control Company (TAQCC). Tehran's Online Noise Pollution Data Archive. Tehran: Tehran Municipality; 2019. Contract No.: 2019/01/02. http://airnow.tehran.ir/home/AirQuality.aspx. Accessed 22 November 2019

\section{Publisher's Note}

Springer Nature remains neutral with regard to jurisdictional claims in published maps and institutional affiliations.

Ready to submit your research? Choose BMC and benefit from:

- fast, convenient online submission

- thorough peer review by experienced researchers in your field

- rapid publication on acceptance

- support for research data, including large and complex data types

- gold Open Access which fosters wider collaboration and increased citations

- maximum visibility for your research: over $100 \mathrm{M}$ website views per year

At $\mathrm{BMC}$, research is always in progress.

Learn more biomedcentral.com/submissions 